\title{
MORFOLOGÍA DIACRÓNICA DEL ESPAÑOL: LAS FÓRMULAS DE TRATAMIENTO
}

\author{
Ángeles Líbano Zumalacárregui \\ Universidad del País Vasco
}

\section{INTRODUCCIÓN.}

Entendemos por fórmula de tratamiento los distintos procedimientos que emplea la primera persona, llamada también persona locutiva, para dirigirse a la segunda, su interlocutor, o persona alocutiva. Dichos procedimientos toman la forma de un pronombre o sintagma nominal, simple o compuesto, y a su vez éstos cumplen la función sintáctica de sujeto, por lo que se habrá de considerar su relación con la persona verbal, o de complemento. Se prestará atención además a la concordancia de dichas formas con los pronombres personales átonos y con los posesivos.

Con relativa frecuencia leemos en los autores clásicos, gramáticos y literatos, observaciones y comentarios acerca del correcto uso y empleo de las fórmulas de interlocución; así, J. de Valdés a una pregunta de Marco con motivo del empleo de la $d$ en las segundas personas de los imperativos advierte :

Póngala por dos respectos: el uno, por henchir más el vocablo, y el otro porque aya diferencia entre el toma, con el acento en la $o$, que es para cuando hablo con un muy inferior, a quien digo tú, y tomad, con el acento en la $a$, que es para cuando hablo con un casi igual, a quien digo vos $^{1}$;

por su parte, el maestro G. Correas, en el Arte de la Lengua Castellana, advierte $^{2}$ :

1 Diálogo de la lengua, ed. J. F. Montesinos, Madrid, Clásicos Castellanos, tomo 86, 1928, págs. 67-70.

2 Madrid, Anejo LVI de la RFE, 1954, pág. 368. 
De vos tratamos a los criados y mozos grandes, y a los labradores y personas semejantes; $y$ entre amigos donde no hay gravedad ni cumplimiento se tratan de vos. $\mathrm{Y}$ aun en razonamientos delante de reyes, $\mathrm{y}$ dirigidos a ellos, se habla de vos con debido respeto $\mathrm{y}$ uso antiguo.

Las citas podrían multiplicarse, pero se pueden encontrar recogidas en los diversos autores que se han ocupado de este tema concreto ${ }^{3}$. Los comentarios de nuestros escritores clásicos son también emotivos: las alusiones de B. de Gracián en su Criticón son continuas, y no sólo inserta una clara gradación de expresiones respetuosas, sino que informa además del justo empleo del vos ${ }^{4}$. En las páginas del Buscón de F. de Quevedo hemos encontrado notas aclaratorias y jocosas de ciertos tratamientos:

He vendido hasta mi sepultura, por no tener sobre qué caer muerto, que la hacienda de mi padre [...] se perdió en una fianza. Sólo el don me ha quedado por vender, y soy tan desgraciado que no hallo nadie con necesidad dél, pues quien no le tiene por ante, le tiene por postre, como el remendón, azadón, pendón, blandón, bordón, y otros asi ${ }^{5}$.

Llegué y ya estaban allí las dichas y los caballeros y todo. Recibiéronme ellas con mucho amor, y ellos llamándome de vos, en señal de familiaridad (Libro, $3 .^{\circ}$, cap. 7 ).

También en los documentos de C. Colón se hallan datos ilustrativos:

Así que, después de aver echado fuera todos los judios [...], mandaron Vuestras Altezas a mi que con armada suffiçiente me fuese a las dichas partidas de India, y para ello me hizieron grandes mercedes y me ennobleçieron, que dende en adelante yo me llamase $d o n^{6}$.

Por otro lado, debemos reseñar el atractivo que esta faceta tan variada de nuestra morfología histórica ofrece a los investigadores de la historia de nuestra lengua española; el ya tradicional y preciso trabajo de R. Lapesa ${ }^{7}$ no ha sido superado, pero si completado con los de otros lingüistas y literatos preocupados en el análisis de las formas de interlocución en nuestros

3 Cf., por ejemplo, J. Plá Cárceles, "La evolución del tratamiento 'vuestra merced" ", $R F E, \mathrm{X}, 1923$, págs. $245-280$, págs. 246 y sigs., y P. P. Rogers, “The forms of address in the Novelas ejemplares of Cervantes". The Romanic Reviezv, New York, 1924, páginas 105-120, págs. 106 y sigs., entre otros.

4 J. M. Enguita, "Fórmulas de tratamiento en El Criticón", Actas de la I Reunión de Filólogos aragoneses, Zaragoza, 1986 (separata), pág. 298.

5 La vida del Buscón llamado Pablos. Edición crítica y estudio preliminar de F. Lázaro Carreter, Salamanca, 1980, libro 2. ${ }^{\circ}$, cap. V.

6 Cristóbal Colón, Textos y documentos completos. Prólogo y notas de C. Varela. Madrid, Alianza, 1984, pág. 15.

7 "Personas gramaticales y tratamientos en español", Homenaje a Menéndez Pidal, Madrid, 1970, págs. 141-167. 
clásicos: véase a este respecto particular la tesis doctoral de $\mathrm{N}$. Ly ${ }^{8}$, o las contribuciones sobre Calderón ${ }^{9}$, Cervantes ${ }^{10}$ y Gracián ${ }^{11}$. No faltan en nuestros días eruditos interesados por los rápidos movimientos del lenguaje, que hicieron desaparecer el vos respetuoso de la lengua clásica, y hallaron en vuestra merced, usted su sustituto; este sintagma se oye hoy esporádicamente en boca de los jóvenes, ya que éstos prefieren el familiar $t u^{12}$.

Así pues, se puede afirmar que uno de los aspectos más cambiantes de la lengua son las formas utilizadas para saludar, los tratamientos, expresiunes afectuosas, injuriosas, etc.; a manera de ejemplo citamos el siguiente: en $1958 \mathrm{~W}$. Beinhauer ${ }^{13}$ afirmaba que con la expresión vocativa tio se designaba a cualquier persona, pero que debia usarse ésta con algún cuidado, pues tenía significado despectivo; dos décadas después, V. Alba de Diego y J. Sánchez Lobato ${ }^{14}$ nos anuncian que entre la juventud el sintagma tio se ha convertido en una forma de interlocución natural en el tratamiento nominal entre chicos, desprovisto ya de cualquier matiz despectivo.

\section{Comentario SOBRE LAS FóRMULAS DE INTERLOCUCIÓN EN NUESTRo CORPUS,}

Es evidente, pues, la inquietud que los tratamientos y su evolución han suscitado entre los estudiosos, pero no es menos evidente que la totalidad de los análisis se fundamentan en obras de carácter literario, y que éstas reflejan por lo general la variedad culta del idioma; asi, R. Lapesa (op. cit.) señala el contraste entre la ceremoniosidad nobiliaria del Poema del Cid y las frases llanas de los fueros municipales, buen indice del lenguaje empleado por la gente llana. La observación de Lapesa acerca del interés de la documentación política y religiosa figura con frecuencia entre las afirmaciones de prestigiosos lingüistas peninsulares; ya J. Mondéjar nos advertia hace po-

8 La poétique de l'interlocution dans le theatre de Lope de Vega. Institut d'études ibèriques et ibéro-americaines de l'Université de Bordeaux, 1981.

- M. Engelbert, "Las formas de tratamiento en el teatro de Calderón", Hacia Calderón. II, Coloquio angloamcricano, Hamburg-Berlin-New York (1983) págs. 191-200, y H. Flasche, "La sintaxis pronominal y la forma dramática en las obras de Calderón". ib. supra, págs. 201-215.

${ }^{10}$ Vid. nota 3 y A. Saint Clair Sloan, "The pronouns of address in Don Quijote", The Romanic Review, New York, XIII, 1922, págs. 65-76.

11 Vid. nota 4.

12 Ya en 1968, Dámaso Alonso ("La muerte del usted", en Del Siglo de Oro a este siglo de siglas [2.a ed.], Madrid, Gredos, 1968, págs. 264-267, pág. 266), se cuestionaba "¿Va a extinguirse el usted en España? ¿Va a quedar relegado a una antigualla solemne, una especie de vuecencia? Mutilaciones semejantes han tenido otras lenguas".

13 El español coloquial, Madricl, Gredos, 1963, pág. 25.

14 "Tratamiento y juventud en la lengua hablada. Aspectos sociolingüísticos", $B R A E$, LX-CCXIX, 1980, págs. 95-129, pág. 119. 
cos años que el enfoque de las historias del español es elitista, podemos decir que con ellas se ofrece la historia de la lengua literaria; por tanto, "hay que aspirar a escribir la historia social de la lengua, en la que merece parigual tratamiento al de la lengua de las corrientes literarias, la de las corrientes políticas, religiosas y científicas $[\ldots]$ es necesario tener en cuenta desde las actas de Cortes, pasando por los fueros, hasta las escrituras de dote" 15 .

Nuestro propósito es cubrir esta laguna, mediante el espigueo de las formas de interlocución en los documentos notariales, reales y religiosos de los siglos XII al XV, de particular importancia para el estudioso de las variaciones espacio-temporales del lenguaje, al figurar en ellos el lugar y el año en que se redactaron: nos pareció además interesante analizar - puesto que en los mencionados artículos sobre Calderón, Lope, Cervantes, etc., se intenta reflejar el lenguaje oral- el género epistolar castellano, desde el siglo $\mathrm{xv}$ al XVII, centuria esta última en la que se van estableciendo de un modo más o menos definitivo el uso de los tratamientos: el pronombre vos adquiere un valor familiar y amistoso ${ }^{16}$; como tratamiento respetuoso había comenzado a utilizarse vuestra merced ${ }^{17}$; y el de tercera persona, él/ella, queda fijado en este siglo - los gramáticos del Siglo de Oro, Correas y Salazar, dan pruebas evidentes del empleo de este pronombre como forma regular ${ }^{18}$ - En lo que a la situación geográfica se refiere, hemos preferido la zona castellana, puesto que otras áreas dialectales —el leonés por ejemplo- mantienen ciertos arcaísmos.

En uno de los textos seleccionados, el Epistolario español, hemos descubierto ciertas normas clásicas, y más modernas, sobre la manera idónea de dirigirse a otra persona, de saludarle; así como la denuncia tácita del abuso del empleo de los títulos:

Es pues vuestra duda y demanda querer saber de mi qué harán dos hombres de bien cuando se topan, es a saber, con qué palabras se han de saludar cuando se ven, y qué dirán el uno al otro cuando se despiden [...]. A uno que me merece merced, decirle vos, y al que merece vos decirle merced, y al que merece ilustre, llamarle magnífico [...]. Cuan justo es que el platero sepa una taza, y el sacerdote decir una misa [...] tan justo es que el buen cortesano sepa qué cosa es la buena crianza (BAE, I, Epistola $1 .^{a}$ de A. de Guevara (1533).

15 "Lingüística e historia", REL, 1980, págs. 1-48, pág. 27.

18 Ello no obstante, J. Covarrubias, Tesoro de la lengua castellana o española, Madrid, 1611, s. v. vos, advierte que no siempre era bien recibido.

17 N. Ly, La poétique ..., pág. 42.

18 J. Plá Cárceles, "La evolución...", pág. 248, y W. E. Wilson, "El and ella as pronouns of address", Hispania, XXIII, 1940, págs. 336-340, pág. 336. 
Sabemos que solamente los soberanos, y aún no todos, ponían el don antes de su nombre. Los duques y grandes señores lo tomaron después con condescendencia de los reyes [...] esto, que pareció justo, demostró cuanto lo era más el rigor antiguo, pues en pocos años ya se propagó la donemanía (perdonen Vuestras Mercedes la nueva voz) (BAE, I, 2. ${ }^{\text {a }}$ parte, Carta $L X X X$ de José Cadalso) (1768).

\section{Fórmulas de tratamiento.}

Los datos obtenides en los textos seleccionados nos han llevado a agrupar las fórmulas de interlocución en dos apartados: el tratamiento pronominal $y$ el tratamiento nominal.

\subsection{Tratamiento pronominal.}

3.1.1. Los documentos firmados por un notario, las concesiones reales y los privilegios de los obispos llevan el pronombre personal de primera persona $y o$; en los textos del xı-xıI figuran además con asiduidad las variantes ego, io. Por otro lado, como con justeza indicaba R. J. Cuervo ${ }^{19}$. puesto que hay cierta delicada repugnancia a empezar un escrito con el presuntuoso $y o$, tras el pronombre se añade el nombre del personaje que redacta el documento, o simplemente se suprime éste:

Et sennor, yo, Ferrand Martincz, escriuano publigo a la vuestra merçed en Avila (Barrios, Avila, doc. 147) (1292).

Ego, don Ordonno, fi de Martín Ferrandez et Petro Martinez ... uendimus monasterium Sancti Saluatoris (M. Pidal, Docs., doc. 14) (1156).

Et a lo que faziestes saber que en el castiello avrie mester más compañia et mas vianda $[\ldots]$ saber que cnvío mandar a García Joffre $[\ldots]$ et bien creo que lo fará (Estal, Inéd. Alf. X, doc, 5) (1276).

Además, durante toda la Edad Media y hasta 1493, los documentos regios emplean el denominado plural mayestático, nos, uso que arranca de la cancillería imperial, y es adoptado por las jerarquias superiores, temporal y espiritual ${ }^{20}$, para más tarde ser utilizado por diversos $y$ variados personajes:

Todas estas cosas dichas de suso, que recontadas sson otorgamos nos ol $\mathrm{Ca}$ bildo de la dicha Eglesia (Barrios, Avila, doc. 87) (1261).

19 Apuntaciones críticas sobre el lenguaje bogotano, Bogotá, BICC, 1955, pág. 329.

20 Cf. Lapesa, "Personas gramaticales ...", pág. 141. 
Connosçida cosa sea a quantos esta carta vieren como nos Frey Domingo Suárez, por la merçed de Dios obispo de Ávila (Barrios, Avila, doc. 94) (1270).

Nos Ruy Garçia de Villalpando, doctor en leyes, notario del reyno de León (Ubieto, Cuéllar, doc. 209 (1442).

Nos el rey y la reyna de Castilla [...] por fazer bien e merced a uos (Torre, doc. 287) (1493).

El plural del pronombre de primera persona es nos; a partir del siglo XIV aparecen tímidos ejemplos del compuesto nosotros junto a nos: ambos sintagmas pronominales se mantienen durante el siglo $\mathrm{xv}$, pero ya en el siglo xvI, nosotros resulta prácticamente exclusivo ${ }^{21}$ :

Et sobre todo esto [...] nos Pascual Gómez e Gonçalvo Matheos e Blasco Munnoz (Barrios, Avila, doc. 87) (1261).

Sepan quantos esta carta de procuración vieren commo nos Johan Alfonso cavallero e Alvar López de Segovia e Johan Alvarcz... (Ubieto, Cuéllar. doc. 237) (1430).

nos los clérigos [...] somos tenudos e obligados a pagar con ellos en çiertas cosas $[\ldots]$ de las quales [...] nosotros dezimos e alegamos que ... (Ubieto, Cuéllar, doc. 224) (1427).

Los grandes y graves y verdaderos trabajos que padecemos nosotros nos los buscamos (BAE, I, Epistola LVIII de A. de Guevara) (1524).

3.1.2. Para la segunda persona del singular, nuestro corpus no ofrece el sintagma tú hasta 1460 , se encuentra en una carta de Fernando del Pulgar a su hija monja ${ }^{22}$; posteriormente, en los textos del xvi sólo A. de Guevara trata de $t \hat{u}$ a un judio ${ }^{23}$. A partir del xvir, resulta habitual el uso del $t u ́$ familiar y solidario. Estos datos coinciden con lo señalado al respecto por los tratadistas, quienes advierten que tú se emplea en el siglo xvi dirigido a personas de diferente rango y en el entorno familiar entre madre e hija, marido y mujer, etc., y que denota o gran superioridad en quien lo daba, o superioridad y cariño ${ }^{24}$.

21 Los datos corroboran la cronología establecida por Gessner, "Das Spanische Personal Pronomen", SPRH, XVII, 1893, pág. 3; apud S. Gili Gaya, "Nos-otros, vosotros", RFE, XXX, 1946, págs. 108-117, pág. 109, nota 1.

22 "E tí, amada fija, si criándote en nuestra casa tú hobiste alguna buena doctrina, debes pagarnosla en oraciones", BAE, I, Letra XXIII.

23 "Pues para entendimiento desto has de saber, judio honrado, que nunca cosa hace y promete nuestro Dios en este mundo [...] Bien te acordarás que en esa sinagoga de Nápoles disputamos y nos barajamos tú y yo sobre querer tú defender la letra seca del Testamento viejo", BAE, I, 2. pte., Epistola X.

24 Cf. H. Keniston, The Syntax of Castillian Prose. The Sixteenth Century, Chi- 
El empleo del pronombre vos como tratamiento respetuoso para el interlocutor figura ya en los últimos tiempos del Imperio romano, dirigido fundamentalmente al emperador (Lapesa, op. cit., pág. 144); eventualmente, el vos se extendió como tratamiento hacia otras figuras del poder ${ }^{25}$. Con la excepción del rumano, las lenguas románicas mantuvieron durante mucho tiempo este pronombre de respeto ${ }^{26}$, y en concreto, en el romance peninsular es ya usual y frecuente en los primeros documentos literarios ${ }^{27}$. En los textos que hemos seleccionado para nuestro trabajo, el vos, indicativo de respeto $\mathrm{y}$ reverencia, es general en los testimonios del xili al $\mathrm{xv}, \mathrm{y}$ permanece hasta los del siglo xvi :

Nos, don Sancho [...] por esti bien que uos, Johan Diaz, fazedes et fiziestes et faredes a la casa de Sancto Toribio (M. Pidal, Docs., doc. 34) (1284).

to que uos, Pidro Felices, haueys a dezir al illustre infante don Enrique (Torre, doc. 84) (1489).

él hizo y deshizo reyes en tres semanas, lo cual vos no habéis hecho en ocho meses (BAE, I, Epistola XVIII de A. de Guevara) (1521).

El vos plural referido a varias personas es conún en los textos del xiII y xiv; la forma compuesta, vosotros, resulta la regular a partir del xv, "época en que ambas formas (nosotros y vosotros) habían rebasado ya su significación originaria y tendían a convertirse en las únicas usuales para expresar el plural" 28 :

Vi vuestra carta $[\ldots]$ et a los que vos dezides que por razón que tenedes muchos moros derredor de vos et que vos avedes a guardar tan bien daquellos que son de paz (Estal, Inéd. Alf. X, doc. 5, El rey Alfonso al concejo de Orihuela) (1276).

Nos don Ferrando [...], por quanto vosotros Steuan Pérez y (un claro) de Sancta Fimia ... (Torre, doc. 93) (1485).

3.1.3. Descle los textos del xiI, nuestros escritos emplean con notoria regularidad el pronombre de tercera persona él/ella para referir a una persona mencionada en líneas anteriores:

cago, The University of Chicago Press, 1937, § 4.41, y T. Rogers, "The form of address ...", págs. 107 y sigs.

25 R. Brown and A. Gilman, "The pronouns of Power and Solidarity", T. Sebeok, Style in the Language, Cambridge, Mass., 1960, págs. 245-276, pág. 255.

26 W. Meyer-Lübke, Grammaire des langues romanes, t. III, Syntaxe, París, H. Welter, 1900, § 97.

27 S. Fernández Ramírez, Gramática española. 4. El verbo y la oración, Madrid, Arcos, 1984, § 13.1 .

28 Gili Gaya, “Nos-otros, vos-otros ...”, pág. 112. 
Et sobre todo esto, que dió don Esteban Domingo, [...], nos Pascual Gómez [...] que fincamos ordenadores [...] pora meter todo lo que él auie de meter por él (Barrios, Avila, doc. 87) (1261).

yo dona Theresa Sánchez ffago este pleyto a don Rodrigo Gonçaluez mjo

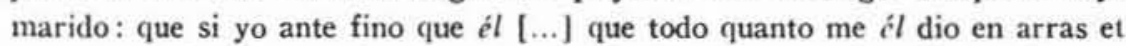
quanto me $i ́ l$ dio por míos derechos... (M. Pidal, Docs., doc. 320) (1234).

Este uso temprano del personal $e l$ resulta ser un dato destacable si se considera que los gramáticos y tratadistas de la Edad de Oro certifican que el empleo del sintagma pronominal, él, como un modo de tratamiento entre el vos desgastado semánticamente y el vuestra merced indicativo de respeto y reverencia; a este respecto, G. Correas señala ${ }^{29}$ : "El usan los mayores con el que no quieren darle merced, ni tratarle de vos, que es más bajo y propio de amos a criados. La lengua vulgar y de aldea que no tiene uso de hablar con merced, llama de él al que quiere honrar de su jaez" ${ }^{30}$. No obstante, el pronombre tardó en llegar a las gramáticas y su generalización fue muy lenta, ya que en su lugar figuraba aquel con relativa frecuencia ${ }^{31}$. Un ejemplo claro del valor y empleo de esta variante constituye el siguiente comentario tan citado de Antonio de Guevara :

Como un caballero valeroso y generoso, aunque mal criado, le oyese yo siempre decir a cada uno con quien hablaba, vos, vos, y él, él, y que nunca decía merced, díjele yo: Por mi vida, señor, que pienso muchas veces entre mí, que por eso Dios ni el Rey nunca os hacen merced, porque jamás llamáis a ninguno merced (BAE, I, Epistola) (1529).

\subsection{Tratamiento nominal.}

En los escritos que comentamos, el nombre propio y el pronombre personal suelen a menudo evitarse por considerarse nominaciones personales y concretas; así, los firmantes designan a la persona a la que se dirigen con sintagmas sustantivos, indicativos de algún atributo o cualidad.

3.2.1. Como era de esperar, el sustantivo de mayor divulgación es mer$c e d$, el cual, precedido del posesivo vuestra, figura en nuestros textos refiriéndose en principio al rey y al príncipe; después esta forma alocutiva la

29 Arte de la lengua castcllana ..., pág. 233.

30 Por su parte, el gramático español Ambrosio de Salazar, en su Espejo general (1615) añade: "Hay cuatro maneras de cortesía en nuestra lengua : una de vucsa merced, otra de él, otra de vos, otra de tú $[\ldots]$, la segunda de él [...] a gente amigos y familiares."

31 M. Alvar y B. Pottier, Morfologia histórica del español, Madrid, Gredos, 1983, $\S 92.1 .1$. 
adoptan las altas esferas y dignidades para resultar ser el tratamiento general mediante el cual un inferior se refiere a un superior, y permanecer como fórmula de respeto entre personas de idéntica condición social.

vuestro servidor e arçediano de Cuéllar beso vuestras manos e me encomiendo a buestra merced (Ubieto, Cuéllar, doc. 88, al obispo de Segovia).

Señor mío, no ha sido mi intento en esta carta más de hacer saber a vuestra merşed, que yo por la misericordia de Dios estoy contento (BAE, I, 2. ${ }^{a}$ parte, Fray Fco, dc Ortiz a su hermano) (1538).

las palabras que me refieren de vuestra mersed algunos que aportan por acá (BAE, I, 2. ${ }^{a}$ parte, Carta de A. Pérez a su mujer) (1601).

Con arreglo a lo ya apuntado por Lapesa y Plá Cárceles (op. cit., págs. 146 y 245 , respectivamente), nuestro corpus ofrece testimonios sueltos en los documentos del $\mathrm{xv}$, de equivalencia entre vuestra merced y vuestra alteza ${ }^{32}$.

3.2.2. En un documento de 1335 del arcediano de Cuéllar al obispo de Segovia, hemos hallado dos veces el compuesto vuestra señoría, poco común en dicha década ${ }^{33}$; la fórmula, ya establecida en el xv, se reserva en principio para los nobles, cardenales, obispos, etc., pero se emplearia después para dirigirse a cualquier familiar $o$ amigo :

señor no podia yo merescer tanta clemencia e humanidad como bucstra señoria cerca de mi e de mis negocios siempre usó (Ubieto, Cuéllar, doc. 88 (1335).

Muy poderoso señor, vuestra señoría me mandó venir a la cura del condestable (BAE, I. lipistola XXIII de F. Pz. de Cibdarreal al rey).

Leído he con atención, y más de una vez, las dos cartas de vuestra señoría (BAE, I, Carta 1. ${ }^{a}$ de J. de Avila para una señora sin titulo).

esa es la carta de que hablamos estotra noche, que vuestra señoria desea tanto ver para aquella persona (BAE, I, Carta CXXVII de A. Pérez a un amigo).

3.2.3. Vucstra alteza es, en los textos del $\mathrm{xv}$ y $\mathrm{xvI}$, el tratamiento respetuoso dirigido a reyes e hijos de reyes: posteriormente se aplica a los príncipes e infantes ${ }^{34}$ :

ca nos entendemos mostrar e allegar ante la vuestra alteza (Ubieto, Cuéllar, doc. 256, al rey Juan $I I)$.

paresçemos ante la vuestra alteza en seguimiento de algunos agravios) ( $\mathrm{Ib}$., doc. 161, al infante don Fernando).

32 " $[\ldots]$ en lo qual la vuestra muy gran altesa guardará el juramento e prometimiento que fizo al tiempo que vnestra merçed reynó", Ubieto, Cuéllar, doc. 256 (1438).

33 Ly, La poétique ..., pág. 61, no halla ejemplos en los textos del xII al xv.

34 Keniston, The Syntax..., \& 4.461, y Fdz, Ramírez, Gramática ... pág. 10. 
El posesivo puede ser $s u$ y sólo excepcionalmente se atestigua $t u ́$ :

apretóme la necesidad de [...] pasar a estos estados y ponerme al amparo de su alteza (BAE, I, Carta de A. Pérez al rey de Francia) (1591).

Clemente [...] mereçe que nos, a los desseos de la tu alteza (Ubieto, Cuéllar, doc. 58).

A partir de la segunda mitad del siglo xv, el tratamiento regio se ve incrementado por el compuesto vuestra nuajestad:

en acorrimiento de las costas del camino que, por mandato de nuestra magestad, fizo al reyno de Nauarra (Torre, doc. 5) (1475).

me han reducido a necesidad forzosa a apartarme dellos y avenirme a los de vuestra majestad a salvar mi persona (BAE, I, Carta de A. Pírez al rey de Francia) (1591).

3.2.4. El gusto por el ceremonial del siglo $\mathrm{xv}$ se complace forjando tratamientos sonoros ${ }^{35}$, y así, en nuestros textos comienzan a aparecer en esta centuria títulos como los de ilustrísimo, dirigido a personas con título:

por carta e ruegos del ilustrísimo don Carlos duque d'Anjou (Torre, doc. 109) (1481),

vuestra serenidat, serenisimo, vuestra real corona, dados al rey:

de derecho y razón es, como vuestra serenidat no ignora (Torre, doc. 84) (1480).

serenísimo rey, nuestro muy caro y muy amado primo (Ib., doc. 71) (1480),

su beatitud, vuestra reverendísima paternidad, prefata santidad ... ofrecidos al papa:

hauemos scripto a la santidat de nuestro santo padre, suplicando su beatitud provea de aquella (Torre, doc. 61) (1475).

Informado somos que, a suplicación de Martín Santjoan sería sometida a vuestra reverendisima paternidad una cavsa (Ib., doc. 46) (1480).

[...] que con mucha instancia supliqueys muy humildement de mi parte a la prefata sanctidat (Torre, doc. 91) (1498).

3s Cf. Lapesa, "Personas gramaticales...", pág. 146. 
3.2.5. Procedimiento común en nuestros textos para expresar la cortesía y otorgar así a una persona cierto tratamiento especial - de respeto y reverencia - es la acumulación de sintagmas nominales y adjetivos ${ }^{36}$ que acompañan a ciertos títulos ofrecidos a las personas regias, dignidades eclesiásticas y personas de título:

al muy alto e muy noble sennor don Sancho por la gracia de Dios rey ... (Barrios, Avila, doc., 147).

fazemos [...] sin mal engaño convusco el onrrado padre señor don Fernando. por la gracia de Dios obispo de Segovia (Ubieto, Cuéllar, doc. 66).

enviamos mucho a saludar a vos, el inclito duque de Bretaña (Torre, doc. 27).

El recurso estilístico es de amplia difusión en los escritos notariales y regios del siglo $\mathrm{xv}^{37}$.

\section{Las Fórmulas de interLocución Y SU CONCORDANCia.}

4.1. El pronombre de primera persona, yo, exige su correspondiente pronombre átono singular $m e$, pero en ocasiones el amanuense, en recuerdo del plural mayestático, escribe nos:

vi vuestra carta $[\ldots]$ et pidiéronme merçed que vos diesse ffueros $[\ldots]$ a aquellos que ssodes y moradores de Orihuela, que nos ffiziestes y nos faredes y serviçio (Estal, Inéd. Alf. X, anexo II, doc. 2).

Por lo demás, el pronombre nos referido a un individuo, concuerda con el verbo en plural y el homónimo correspondiente:

Et nos el Cabildo sobredichho otorgamos e damos poder por lo que nos da el sobredicho don Esteban (Barrios, Avila, doc, 87).

El de segunda persona singular, tú, figura con los posesivos tu/tuyo, $-a$, preposición más $t i$, y el sintagma contigo:

merece que nos a los desseos de la $t u$ alteza otorguemos $a$ ti la petición que a nos fue dada de $t u$ parte (Ubieto, Cúlllar, doc. 58).

de heberme contigo enojado, pésame, más de haber contigo apostado pláceme [...] será pues agora la duda mía y pregunta tuya, por qué habiendo ella sido cautiva y perseguida [...] (BAE, I, Epistola $X$ de A. de Guevara).

36 A. Doppagne, "La expresión de la cortesia", Actas del Tercer Congreso Internacional de Hispanistas, México, 1970, págs. 285-291, pág. 285.

${ }_{37}$ R. Lapesa, Historia de la lengua española, Madrid, Gredos, 1980, págs. 266-267. 
El tratamiento de respeto vos se acompaña del pronombre régimen vos, y sólo a finales del $\mathrm{xv}$ se combina con el moderno os; ambos, vos y os, pueden convivir en un mismo texto:

E diz el Rey que vos diga que su señoria os regrese ese metro (BAE, I. Epistola $X I X$ de F. Pz. de (ibdarreal).

sobre las quales cosas otras diversas ueces nos acordamos hauer hos escrito; e agora postrimeramente desde Caragoça vos escreuimos, rogandovos diessedes orden (Torre, doc. 49).

El plural vosotros suele ir con el átono vos y con una preposición más vos/ vosotros: el pronombre posesivo es siempre vuestro $(s)$, vuestra(s):

sino que vosotros a ellas fuessedes obligados [...] la qual renouaçión, en caso que se fiziesse, haya de ser intimidada a vosotros o al vno de vos o de vuestros factores (Torrc, doc. 262).

4.2. Los sintagmas abstractos vuestra merced, vuestra señoria, vuestra alteza ... exigen la tercera persona del singular del verbo, el pronombre átono $l e$, y los posesivos su, suyo. Si el posesivo empleado con el abstracto es el de familiaridad $t u$, el pronombre régimen es $t e, a t i$ :

quiero decir que $l c$ aprovecharía mucho a vuestra merced considerar que el primero y mayor esposo suyo es Jesucristo (BAE, I, Epistola XII de F. Fco. Ortiz).

Clemente $[\ldots]$ mereçe que nos, a los desseos de la tu alteza $[\ldots]$ otorguemos a ti la petición que a nos fue dada de tu parte (Ubieto, Cuéllar, doc. 58).

\section{El tratamiento y los paradigmas verbales.}

Tras estas consideraciones generales sobre los aspectos particulares que las formas de interlocución ofrecen, presentaremos unos comentarios acerca de los paradigmas verbales que corresponden a la segunda persona, y que presentan rasgos fonéticos destacables.

5.1. En los textos del xiri-xiv es general el mantenimiento del morfema de segunda persona del plural -des en las segundas personas del presente, imperfecto y futuro:

sepades que don Fray Domingo Suárez, obispo de Avila, se me querelló e dize que non queredes dar sus diezmos (Barrios, Avila, doc. 93) (1268). 
Et commo pediades mercet que mandasse y lo que touiesse por bien (Estal, Inéd. Alf. X, doc. 2) (1281).

Et quando io mandare partir Orihuela vos me embiarcdes vuestros omnes buenos (Ih., anexo II, (loc. 22) (1265).

Sólo a partir del siglo $\mathrm{xv}$ y con cierta vacilación hallamos voces con su $-d$ perdida conviviendo con ejemplos en su forma plena. Por otro lado, la desaparición de la consonante sonora deja en contacto dos sonidos vocálicos que tienden a su mantenimiento, optan por la solución diptongada o monoptongan:

vos señor, e los más grandes de los grandes que de consuno andáis, me llamades de padre, ca a los más yo vos crié (BAE, I, Epistola LXXXII de F. $P z$. de Villarreal) (1439).

la qual restitución uos hauemos mandado fagades buen complimiento (Torre, doc. 2) (1479).

por mandado de uuestra magestad, [...] dezimos y mandamos [...] le recibaes y pases en conto (Torre, doc. 51) (1479).

vos será dicho lo que havíys de fazer, para que aquellos que exccuteys e pongays por obra [...] (Torre, doc. 8) (1479).

por el poco caso que haués fecho de nuestro screuir, y menos gana que haués mostrado de nos complazer" (Ib., doc. 121) (1489).

Interesa en este punto destacar el conservadurismo del lenguaje cancilleresco, reflejado por la convivencia en fecha tardía - siglo $\mathrm{xv}$ - de formas con $\mathrm{y}$ $\sin -d$ - con la solución moderna que se decide por el diptongo ; téngase presente que la Gramática de Nebrija (1492) ofrece ya en los paroxítonos el paradigma con $-d^{38}$.

5.2. El perfecto ofrece con cierta asiduidad la desinencia etimológica -stes, los primeros ejemplos con $i$ analógica datan de finales del $\mathrm{xv}^{39}$ :

[...] e fiçiestes hi IIII ruedas en una casa et partiestes connusco (M. Pidal, Docs., doc. 162) (1211).

después del correu, con el qual hauisasteis de la muerte del Papa Sixto, hauemos recebido tres cartas (Torre, doc. 130) (1484).

38 R. J. Cuervo, "Las segundas personas...", pág. 74, advierte cómo el lenguaje cancilleresco es por fuerza conservador al ser el último en abandonar los arcaísmos.

${ }_{39}$ R. Souza, "Desinencias verbales correspondientes a la persona vos/vos-otros en el Cancionero General (Valencia, 1511)", Filología, Buenos Aires, 1964, págs. 1-95, pág. 3 . 
Plugo nos saber, assi particularmente como lo screuistes, el caso de los XXXVI moros [...]. Plaze nos la dilignecia que pusisteis en embiar nuestras letras $(I b$. , doc. 4) (1494).

Para la segunda persona del singular se lee la variante etimológica en -ste; una vez, en una carta de Juan de Ávila de 1569, figura la $-s$ analógica:

si te dan alguna que es muy rica, afrentaste de contar su parentela (BAE, I, Epistola LI de A. de Guevara) (1524).

dijome pues el emperador Tito estas palabras: Dime, hombre, quien eres [...] que hiciste, que delitos comctiste, por que aqui fuiste traido (BAE, I, Epistolu $X X I V$ de A. dc Guevara) (1529).

mucho consuelo me distes con que guardaste bien el concierto que entre vos y mi quedó (BAE, I) (1569).

\section{Conclusiones.}

Si bien a lo largo de estas páginas se han ido reseñando los aspectos más interesantes en el empleo de los tratamientos, como colofón deseamos resaltar los siguientes:

- En el empleo de las formas pronominales, los textos notariales, eclesiásticos y reales no ofrecen casos del tú familiar; sólo en las epístolas familiares hallamos un tardío empleo del pronombre (1460). Nótese que, según Lapesa, en el Poema del Cid el héroe trata de tú a los parientes y vasallos jóvenes. Por el contrario, para la tercera persona, estos mismos diplomas utilizan con regularidad el pronombre él/ella para referir a personas mencionadas anteriormente, desde el xiII.

- El tratamiento con sintagmas abstractos es, en rasgos generales, idéntico al reseñado por otros estudiosos. El sustantivo de mayor divulgación es merced, el cual, precedido de vuestra, refiere en principio al rey, y después al príncipe y otras dignidades civiles y eclesiásticas; vuestra alteza y vuestra majestad están reservados para dirigirse también a los reyes, a los príncipes e infantes, y permanece hasta nuestros días; mientras que vuestra señoría, frecuente sólo a partir del xv, según los eruditos, lo hemos hallado nosotros en 1335. En nuestro corpus no hay casos de vuestra excelencia.

- El conservadurismo del lenguaje cancilleresco se refleja en el uso de la variante latino-romance del pronombre personal de primera persona 
ego, io junto a la moderna yo, y en el mantenimiento, hasta fecha tardía, siglo $\mathrm{xv}$, de la desinencia de segunda persona del plural -des en formas paroxitonas.

\section{Abreviatl ras de las fuentes utilizadas.}

BAE, I = Biblioteca de Autores Españoles, tomo XII. Epistolario español de cartas de españoles ilustres antiguos y modernos, I, Madrid, 1945.

Barrios, Avila = A. Barrios García, Documentación medieval de la catedral de Avila. Universidad de Salamanca, 1981.

Estal, Inéd. Alf. $X=\mathrm{J}$. M. Estal, Documentos inéditos de Alfonso $X$ cl Sabio y dcl Infantc su hijo don Sancho, Alicante, 1984.

M. Pidal, Docs. = R. Menéndez. Pidal, Documentos lingüisticos de España, I (Reino de Castilla), reimpresión, Madrid, 1966

Torre = A. de la Torre, Documentos sobre las relaciones internacionales de los Reyes Católicos (4 vols.), Barcelona, CSIC, 1949-1962.

Ubieto, Cuéllar = A. Ubieto, Colección diplomática de Cuéllar, Segovia, Excma. Diputación Provincial, 1961. 